\title{
Safety and efficacy of methyldopa and labetalol in controlling blood pressure in hypertensive disorders of pregnancy
}

\author{
Mary Rohini Pentareddy ${ }^{1}$, Shailendra D. ${ }^{2}$, Prasuna G. ${ }^{2}$, Subbaratnam Y. ${ }^{2}$, \\ Naresh D. T. V. ${ }^{2}$, Rajshekar Katta ${ }^{2}$
}

\author{
${ }^{1}$ Department of Pharmacology, \\ R.V.M. institute of medical \\ sciences and RC, \\ Laxmakkapally, Siddipet, \\ Telangana, India \\ ${ }^{2}$ Department of Pharmacology, \\ Mediciti institute of medical \\ sciences, Medchal, Telangana, \\ India
}

Received: 02 February 2017 Accepted: 01 March 2017

*Correspondence to:

Dr. Mary Rohini Pentareddy, Email:

drmaryrohini@yahoo.co.in

Copyright: (c) the author(s), publisher and licensee Medip Academy. This is an openaccess article distributed under the terms of the Creative Commons Attribution NonCommercial License, which permits unrestricted noncommercial use, distribution, and reproduction in any medium, provided the original work is properly cited.

\begin{abstract}
Background: Hypertensive disorders represent the most common medical complication of pregnancy, with a reported incidence of 6-10\% and accounts for $15 \%$ of maternal mortality. Effective management of pregnancy induced hypertension is vital to improve maternal and foetal outcomes. As data are scarce on comparison of labetolol and methyldopa this study was undertaken. The objective of present study is compare the efficacy and safety of Labetalol versus Methyldopa in the management of Mild to Moderate pregnancy induced hypertension. To evaluate effect of both drugs on maternal and foetal outcomes. Methods: A comparative observational study is designed. 30 patients who received methyldopa and 30 patients who received labetalol were included in the study. Methyldopa was started at a dose of $250-500 \mathrm{mg}$ thrice daily while labetalol was started at a dose of 100-400 mg twice daily. Patients were followed up during antenatal, intrapartum and postpartum period for efficacy, safety, maternal, and perinatal outcomes.

Results: Methyldopa and Labetalol reduced mean systolic and mean diastolic blood pressures significantly. safety profile of both drugs was similar. Spontaneous vaginal deliveries were observed more with labetolol significantly. Conclusions: Labetalol is equally efficacious as methyldopa and well tolerated in the treatment of new onset hypertension during pregnancy.
\end{abstract}

Keywords: Adverse effects, Labetalol, Methyldopa, PIH

\section{INTRODUCTION}

Hypertensive disorders are the most common medical complications of pregnancy (6-10\%) and a major cause of maternal morbidity and mortality $(15 \%)$ and foetal morbidity and mortality $(22 \%) .{ }^{1}$ Women with gestational hypertension are at risk for progression to pre-eclampsia, Eclampsia, and abruption. The risks are increased if patients are diagnosed at lower gestational age. ${ }^{1}$ Though hypertensive disorders in pregnancy cannot be prevented, early diagnosis and treatment helps in favourable maternal and fetal outcomes.
The benefits of antihypertensive therapy for mild to moderately increased blood pressure in pregnancy $(\geq 140 / 90$ and $\leq 160 / 110 \mathrm{mmHg}$ ), either chronic or de novo, have not been shown in clinical trials.

A cochrane meta-analysis concluded that there are insufficient data to determine the benefits and risks of antihypertensive therapy for mild to moderate hypertension (defined as blood pressure 140-160mmHG systolic or diastolic blood pressure 90-109 mmHG). ${ }^{2}$ In this meta-analysis, they concluded that the risk of developing severe hypertension is reduced to half by using antihypertensive medications. ${ }^{2}$ 
Hence, it was felt that assessment of efficacy /potential benefit of the use of antihypertensive in women with mild hypertension during pregnancy is essential. Methyldopa is the most commonly used drug for pregnancy induced hypertension but it takes longer time to act. ${ }^{3,4}$ In cases where monotherapy is inadequate to control blood pressure in patients with PIH other drugs have been used. Recent studies have shown labetalol $(\alpha+\beta$ blocker $)$ to give better control of blood pressure compared to other anti-hypertensive agents. ${ }^{3,4}$

Advantage of labetalol is that it is available in both oral and injectable formulations and onset of action is fast compared to methyldopa. Since the literature on comparison of efficacy of these two drugs is scarce, this study was undertaken to compare the efficacy of labetalol versus methyldopa in the treatment of mild to moderate pregnancy induced hypertension.

\section{METHODS}

This comparative, prospective, observational study was conducted in Gynaecology and Obstetric Department of MediCiti Institute of Medical Sciences, over a period of one and half year (November 2012 to June 2014). Sample size was 60 patients (30 patients in each group).

\section{Inclusion criteria}

- All pregnant women with mild to moderate hypertension (systolic BP 140-160 mm of $\mathrm{Hg}$ and diastolic BP 90-110 $\mathrm{mm}$ of $\mathrm{Hg}$ )

- $\quad$ Age of the patient between 18-35 years

- Primigravida or multigravida

- Vertex presentation

- Singleton pregnancy

\section{Exclusion criteria}

- $\quad$ Patient's age more than 35 years.

- Severe pregnancy induced Hypertension (systolic BP $\geq 160 \mathrm{~mm} \mathrm{HG}$; diastolic BP $\geq$ to110 $\mathrm{mm} \mathrm{HG}$ ).

- Severe Pre-eclampsia (severe hypertension with proteinuria $2+$ or more or $2 \mathrm{~g}$ or more $/ 24 \mathrm{hrs}$, headaches, visual disturbances, epigastric pain)

- Chronic hypertension

- Multiple pregnancy

- Bad obstetric history

- Gestational diabetes

- Cardiac conditions complicating pregnancy

- Renal dysfunction

30 patients received methyldopa and 30 patients received labetalol. Patients received treatment as per the assessment of the treating obstetrician. The study was approved by the institutional ethics committee of the hospital. Informed consent was obtained from all the patients before enrollment. Medical and obstetric history was taken and physical examination was conducted at the time of initial recruitment.

Conventional sphygmomanometer was used for BP measurement and phase V Korotokoff sounds were used to define diastolic BP. The measurements were taken in the sitting position in a chair after 20 minutes rest. Two readings were taken 30 minutes apart. Patients who failed to achieve the point of control after initiation of therapy with a maximum of $900 \mathrm{mg} /$ day of Labetalol for at least 72 hours were labelled uncontrolled. Patients who failed to achieve the point of control seven days after initiation of therapy with a maximum of $2 \mathrm{~g} /$ day of Methyldopa continued for at least $72 \mathrm{hrs}$ were labelled uncontrolled. All the patients were followed for $72 \mathrm{~h}$. Blood pressure was measured at $0,6,24,48$ and $72 \mathrm{~h}$ after initiation of antihypertensive drugs.

\section{Statistical analysis}

Data were entered in MS excel 2007, same were exported into STATA (version 10). For normally distributed continuous data, comparison for significance of difference were done by using:

- Student's paired t test for within group before and after treatment.

- Student's unpaired t test was used for comparison of normally distributed continuous data between the two treatment groups.

- Categorical data were analyzed for associations using chi square test.

p value $<0.05$ was considered statistically significant.

\section{RESULTS}

This comparative study was carried out in Obstetrics and Gynecology Department in MediCiti Institute of Medical Sciences, Ghanpur, Medchal. 30 patients receiving Methyldopa and 30 patients receiving labetalol were included in this study. The mean age in methyldopa group was $22.3 \pm 3.85$ and mean age in labetalol group was $23.23 \pm 4.1$ in methyldopa group $73 \%$ of patients were between $19-24 \mathrm{yrs}$, whereas $50 \%$ of patients of were in between 19-24yrs in labetalol group.

\section{Gestational age at presentation (no. of patients)}

23 patients in both groups presented for the first time with hypertension before 36 weeks.7 patients in Methyldopa group and 6 patients in labetalol group presented at 36 weeks and only 1 patient in labetalol group was diagnosed with $\mathrm{PIH}$ at 37 weeks.

Comparison of drug impact on mean SBP at the time of admission

Figure 1 shows the effect of methyldopa and labetalol on Mean systolic blood pressure. Methyldopa reduced blood 
pressure from mean systolic blood pressure $143.33 \pm 6.06$ to $122.66 \pm 4.58 \mathrm{~mm}$ of $\mathrm{Hg}$. There was a significant reduction in blood pressure before and after treatment, ( $p$ value <0.001). Labetalol reduced mean systolic blood pressure of $143.67 \pm 6.69$ to $121.66 \pm 5.23$. With labetalol also there was a significant reduction of blood pressure before and after treatment, ( $p$ value <0.001). On comparing methyldopa and labetalol group, difference in fall in systolic BP was not statistically significant, ( $p$ value $>0.005$ ).

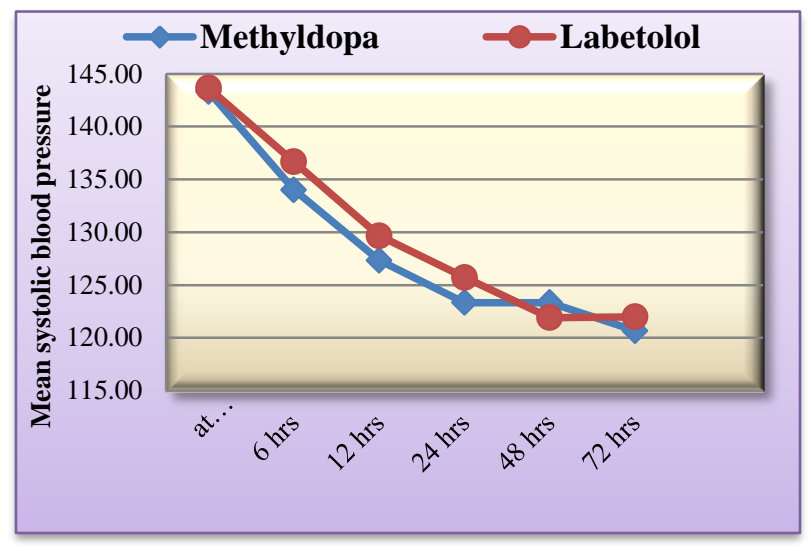

Figure 1: Comparison of drug impact on mean SBP at the time of admission.

\section{Comparison of drug impact on mean DBP in both groups}

The Figure 2 which is shown below shows effect of methyldopa and labetalol on diastolic blood pressure. methyldopa reduced blood pressure from mean diastolic blood pressure $94.00 \pm 4.98$ to $82.00 \pm 5.61 \mathrm{~mm}$ of $\mathrm{Hg}$. There was significant reduction in blood pressure before and after treatment ( $\mathrm{p}$ value $<0.001$ ).

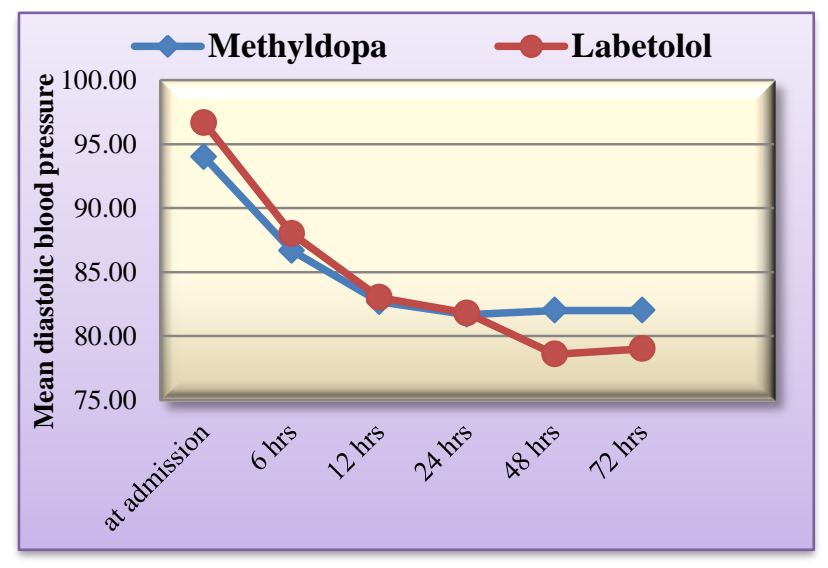

Figure 2: Comparison of drug impact on mean DBP at the time of admission.

Labetalol reduced Mean diastolic blood pressure of $96.67 \pm 4.79$ to $79.00 \pm 5.53$. with labetalol, also there was statistically significant reduction of blood pressure before and after treatment ( $\mathrm{p}$ value <0.001). On comparing methyldopa and labetalol group, difference in fall in mean DBP was not statistically significant ( $\mathrm{p}$ value $>0.005)$.

\section{Comparison of mean SBP in both groups at 36 weeks}

Table 1 shows mean systolic blood pressure in Methyldopa group at 36weeks for 23 patients was $123.97 \pm 7.868$ and mean systolic blood pressure in labetalol group at 36 weeks was $123.47 \pm 4.082$.

Table 1: Comparison of mean SBP in both groups at 36 weeks.

\begin{tabular}{|llc|}
\hline & Methyldopa $(\mathbf{N})$ & Labetalol $(\mathbf{N})$ \\
\hline $\begin{array}{l}\text { Mean } \\
\text { SBP } \pm \text { SD }\end{array}$ & $123.97 \pm 7.868(23)$ & $123.47 \pm 4.082(23)$ \\
\hline
\end{tabular}

Comparison of mean DBP in both groups at 36 weeks

Table 2 shows mean diastolic blood pressure in methyldopa group at 36 weeks (follow up visits) for 23 patients (who presented before 36 weeks) was $83.47 \pm 5.832$ and mean diastolic blood pressure in labetalol group at 36 weeks was $81.32 \pm 3.78$ ( 6 patients in methyldopa group and 7 patients in labetalol group presented for the first time at 36 weeks, 1 patient in Labetalol group presented at 37 weeks).

Table 2: Comparison of mean DBP in both groups at 36 weeks.

\begin{tabular}{|llr|}
\hline & Methyldopa $(\mathbf{N})$ & Labetalol $(\mathbf{N})$ \\
\hline Mean & $83.47 \pm 5.832(23)$ & $81.32 \pm 3.78(23)$ \\
\hline SBP \pm SD & & \\
\hline
\end{tabular}

Comparison of mean SBP in both groups at delivery

Figure 3 shows mean systolic BP was $123.66 \pm 10.332$ in Methyldopa group and 121.66 \pm 7.4664 in Labetalol group at the time of delivery. 2 patients in methyldopa group and 1 patient in labetalol group had severe hypertension.

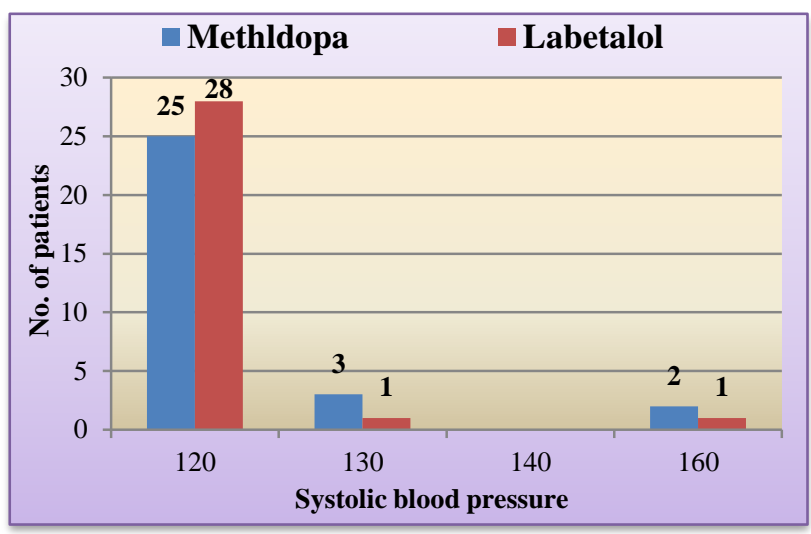

Figure 3: Comparison of mean SBP in both groups at delivery. 
Comparison of mean DBP in both groups at delivery

Figure 4 shows mean diastolic BP was $82.666 \pm 6.914$ in Methyldopa group and $81.33 \pm 5.713$ in labetalol group at the time of delivery. One patient in methyldopa group and one patient in labetalol group developed severe hypertension, there diastolic blood pressure was $110 \mathrm{~mm}$ of $\mathrm{Hg}$.

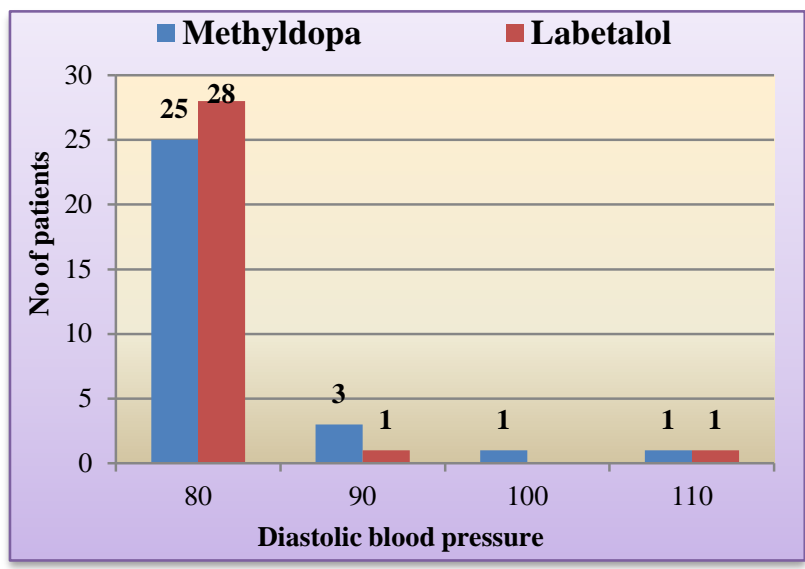

Figure 4: Comparison of mean DBP in both groups at delivery.

\section{Comparison of maternal outcomes in both groups}

Table 3 revealed that $2(6.66 \%)$ patients in Methyldopa group and $1(3.33 \%)$ patient in Labetalol group developed severe hypertension.

Table 3: Comparison of maternal outcomes in both groups.

\begin{tabular}{|lll|}
\hline & $\begin{array}{l}\text { Methyldopa, } \\
\text { N }(\%)\end{array}$ & $\begin{array}{l}\text { Labetalol, } \\
\text { N }(\%)\end{array}$ \\
\hline $\begin{array}{l}\text { Severe hypertension } \\
(160 / 110 \mathrm{~mm} \text { of } \mathrm{Hg})\end{array}$ & $2(6.66 \%)$ & $1(3.33 \%)$ \\
\hline eclampsia & 0 & 0 \\
\hline abruption & 0 & 0 \\
\hline Severe pre eclampsia & 0 & 0 \\
\hline p value & 1 & \\
\hline
\end{tabular}

There was no statistically significant difference between two groups ( $\mathrm{p}$ value $=1$ ). They were given additional drug for control of blood pressure by the treating obstetrician. None of the patients developed other complications like Eclampsia, abruption, and severe pre-eclampsia.

\section{Comparison of adverse effects in both groups}

Table 4 shows that headache was the commonest symptom in both groups. Patients who are on methyldopa developed adverse effects like postural hypotension (2) and drowsiness (2) but there was no statistical difference between two groups.
Table 4: Comparison of adverse effects in both groups.

\begin{tabular}{|ll|l|}
\hline Adverse effects & Methyldopa & Labetalol \\
\hline Postural hypotension & 2 & 0 \\
\hline Drowsiness & 2 & 0 \\
\hline Headache & 5 & 2 \\
\hline Bradycardia & 0 & 0 \\
\hline Depression & 0 & 0 \\
\hline Nausea & 2 & 2 \\
\hline Total & 11 & 4 \\
\hline p value & $(0.0716, \mathrm{NS})$ \\
\hline
\end{tabular}

\section{DISCUSSION}

The major goal of antihypertensive medication in mild to moderate pregnancy induced hypertension is to prevent or treat severe hypertension (generally defined as blood pressure of $\geq 160 / 110 \mathrm{~mm}$ of $\mathrm{Hg}$ ) and its associated complications and to prolong pregnancy as long as possible. Hypertensive disorders seem to complicate approximately $10 \%$ of pregnancies and are important causes of maternal and foetal morbidity and mortality. ${ }^{1}$ In the present study comparison between the antihypertensives, labetalol and methyldopa, in terms of efficacy and safety were assessed. In the present study, the mean age of the patients in the methyldopa group was $22.3 y r s$. The mean age of the patients in the labetalol group was 23.23 yrs. Both groups were statistically comparable $\quad(\mathrm{p}=0.369$, non-significant $) . \quad$ Maximum number of patients were in between 19-24 years, which is supported by Verma et al study. ${ }^{5}$

Both labetalol and methyldopa have reduced mean systolic and diastolic blood pressures significantly. Hence, it can be inferred that starting of antihypertensives in pregnant women with mild to moderate hypertension produces a significant reduction in the absolute Mean values of SBP and DBP and were effective in controlling blood pressure. ( $p$ value $<0.001$, highly significant on comparing methyldopa and labetalol groups, fall in Mean systolic and diastolic blood pressure was not statistically significant between two groups which means both were equally efficacious ( $\mathrm{p}$ value $>0.05)$.

Findings in the present study were comparable with the study of Verma et al who concluded that both drugs are equally efficacious. This study was also comparable with previous studies Redman et al, Sibai et al, Plouin et al, Pickles et al, Sibai BM et al. ${ }^{6-10}$ However, few studies say that labetalol provides more efficient control of BP than methyldopa in the treatment of mild hypertension in pregnancy.

Qarmalawi et al, 1995, 81.4\% patients in labetalol group had a significant fall in MAP as against $68.5 \%$ in patients taking methyldopa. ${ }^{11}$ Subhedar et al, 2013, there was a more significant fall in MAP in labetalol group compared 
to methyldopa group and also time required to control BP was $36.97 \mathrm{hrs}$ in labetalol group and time taken to control BP was $42.22 \mathrm{hrs}$ in methyldopa group. ${ }^{12}$ Lamming et al, there was a highly significant fall in MAP in the group treated with labetalol $(\mathrm{p}<0.001)$ but no significant fall was noted in the group tested with methyldopa ( $p$ value>0.05). ${ }^{13}$ Similar response rates have been found in few more studies like-lardoux's group $82 \%$, Michael $92 \% .{ }^{14}$ Nita et al, compared three antihypertensive drugs in pregnancy induced hypertension and concluded that labetalol is more effective than methyldopa and nifedipine in controlling blood pressure in patients with pregnancy induced hypertension, while methyldopa and nifedipine were equally effective in controlling blood pressure. ${ }^{15}$

In the present study, only one $(3.33 \%)$ patient developed severe hypertension in labetalol group, while $2(6.66 \%)$ patients in the methyldopa group developed severe hypertension, but there was no statistically significant difference between two groups ( $p$ value $=1$ ). In the present study, none of the patients developed other complications like eclampsia, abruption and severe pre-eclampsia.

Findings in the present study were comparable with the study of Verma et al, $4.44 \%$ out of 45 patients in methyldopa group and $6.66 \%$ out of 45 patients in labetalol group developed severe hypertension. ${ }^{5}$ Adverse effects seen with both drugs are known and there was no statistically significant difference between two groups ( $p$ value $=0.0716$, non-significant). In the present study, headache was the most common side effect observed. Present study findings were comparable to Subhedar et al study in which 10 patients $(11.1 \%)$ in methyldopa group and 8 patients $(8.88 \%)$ in labetalol group complained of headache. Findings in the present study were comparable with the study of El-Qarmalawi AM et al, Lamming GD et al, Verma et al. ${ }^{5,11,13}$ In the present study, none of the patients complained of dyspnoea, weakness, depression. In Qarmalawi et al study 3 patients on labetalol complained of dysnoea. ${ }^{11}$

\section{CONCLUSION}

Methyldopa reduced mean systolic and diastolic blood pressures significantly ( $\mathrm{p}$ value $<0.001$ ). Labetalol also reduced Mean systolic and diastolic blood pressures significantly ( $\mathrm{p}$ value $<0.001$ ). There was no statistically significant difference between two groups, from which it can be inferred that labetalol is equally efficacious as methyldopa in the treatment of pregnancy induced hypertension.

Safety profile of labetalol was similar to that of methyldopa. The chances of spontaneous onset of labour were greater in the labetalol group when compared to methyldopa group, ( $p$ value $=0.002)$ which was statistically significant. To conclude, labetalol is a safe drug, equally efficacious as methyldopa and can be used in hypertensive disorders of pregnancy.
Funding: No funding sources

Conflict of interest: None declared

Ethical approval: The study was approved by the Institutional Ethics Committee

\section{REFERENCES}

1. Report of the national high blood pressure education program working group on high blood pressure in pregnancy. Am J Obstet Gynecol. 2000;183(1):S1S22.

2. Abalos E, Duley L, Steyn D, Henderson-Smart DJ. Antihypertensive drug therapy for mild to moderate hypertension during pregnancy. Cochrane Database Syst Rev. 2007;(1):CD002252.

3. Magee L, Duley L. Cochrane study group oral betablockers for mild to moderate hypertension during pregnancy. Cochrane Database Syst Rev. 2003;(3):CD002863.

4. Goodman \& Gilman's The pharmacological basis of therapeutics. $11^{\text {th }}$ ed. 2006:32.

5. Verma R, Lahon K, Tonpay SD, Kale VJ, Jain DK. A comparative randomised controlled parallel group study of efficacy and tolerability of labetalol versus methyldopa in the treatment of new onset hypertension during pregnancy. Int J Life Sci Pharm. Research. 2012;2:23-31.

6. Redman CWG, Gallery ED, Mitchell MD. Fall in BP in response to volume expansion in pregnancy associated hypertension (PE): Why does it occur? BMJ. 1984;2(2):177-82.

7. Sibai BM, Gonzalez AR, Mabie WC, Moretti M. A comparison of labetalol plus hospitalization versus hospitalization alone in the management of preeclampsia remote from term. Obstet Gynecol. 1987;70:323-7.

8. Plouin PF, Breart G, Maillard F, Papiernik E, Relier JP. Comparison of antihypertensive efficacy and perinatal safety of labetalol and methyldopa in the treatment of hypertension in pregnancy: a randomized controlled trial. Br J Obstet Gynaecol. 1988;95:868-76.

9. Pickles CJ, Symonds EM, Pipkin FB. The fetal outcome in a randomized double-blind controlled trial of labetalol versus placebo in pregnancy-induced hypertension. Br J Obstet Gynaecol. 1989;96:38-43.

10. Sibai BM, MabieWC, Shamsa F, Villar MA, Anderson GD. A comparison of no medication versus methyldopa or labetalol in chronic hypertension during pregnancy. Am J Obstet Gynecol. 1990;162(4):960-6.

11. El-Qarmalawi AM, Morsy AH, Al-Fadly A, Obeid A, Hashem M. Labetalol vs methyldopa in the treatment of pregnancy-induced hypertension. Int J Gynecol Obstet. 1995;49:125-30.

12. Subhedar V, Inamdar S, Hariharan C, Subhedar S. Comparison of efficacy of labetalol and methyldopa in patients with pregnancy-induced hypertension. Int J Reprod Contracept Obstet Gynecol 2013;2:27-34. 
13. Lamming GD, Symonds EM. Use of labetalol and methyldopa in pregnancy induced hypertension. $\mathrm{Br} \mathbf{J}$ Clin Pharmacol. 1979;8:217S-22S.

14. Lardoux H, Blazquez G, Leperlier E, Gerard J. Randomized, comparative study on the treatment of moderate arterial hypertension during pregnancy: methyldopa, acebutolol, labetalol. Arch Mal Coeur Vaiss. 1988;81:137.

15. Patel NK, Gadhavi M, Gorasia D, Pandya MR. Comparative evaluation of antihypertensive drugs in the management of pregnancy-induced hypertension. Int J Basic Clin Pharmacol. 2012;1:174-7.

Cite this article as: Pentareddy MR, Shailendra D, Prasuna G, Subbaratnam Y, Naresh DTV, Katta R. Safety and efficacy of methyldopa and labetalol in controlling blood pressure in hypertensive disorders of pregnancy. Int J Basic Clin Pharmacol 2017;6:942-7. 